\title{
Short-Term Haematogical Effects of Androgen Deprivation and Radiotherapy in Prostate Cancer Patients
}

\author{
Gregory P. Swanson*, Kendall Hammonds, Sameer Jhavar \\ Baylor Scott and White Health, Temple, Texas, USA \\ Email: *Gregory.swanson@BSWhealth.org
}

How to cite this paper: Swanson, G.P., Hammonds, K. and Jhavar, S. (2021) Short-Term Haematogical Effects of Androgen Deprivation and Radiotherapy in Prostate Cancer Patients. Open Journal of Urology, 11, 103-111.

https://doi.org/10.4236/oju.2021.114011

Received: March 4, 2021

Accepted: April 5, 2021

Published: April 8, 2021

Copyright ( 2021 by author(s) and Scientific Research Publishing Inc. This work is licensed under the Creative Commons Attribution International License (CC BY 4.0).

http://creativecommons.org/licenses/by/4.0/

\begin{abstract}
Androgen deprivation therapy (ADT) is known to cause a decline in hemoglobin ( $\mathrm{Hgb})$, but the effect on other blood parameters is less well studied. In the lab, androgen manipulation has an effect on leukocyte counts. We evaluated the effects of androgen ablation alone on Hgb, white blood cell (WBC), granulocyte, and lymphocyte counts in 99 prostate cancer patients. In addition, since radiation therapy decreases those counts, we evaluated whether the addition of ADT makes it worse, comparing 162 patients receiving both radiation and ADT to 149 patients with radiation alone. ADT alone did significantly (but minimally) cause a drop in the $\mathrm{Hgb}(\sim 0.5 \mathrm{~g} / \mathrm{dl})$, the WBC $(-0.39 \times$ $\left.10^{3} / \mu \mathrm{l}\right)$ and granulocyte $\left(-0.32 \times 10^{3} / \mu \mathrm{l}\right)$, but not the lymphocyte counts. The combination of ADT with radiation did cause a greater decline in the Hgb levels at the end of treatment, but at follow up there was no difference. There was no additional effect on WBC, granulocytes or lymphocyte counts. Our results confirm clinically that $\mathrm{ADT}$ alone has minimal effect on $\mathrm{WBC}$ and its components and that there is no synergistic detriment of androgen ablation on the effects of radiation therapy on those cells.
\end{abstract}

\section{Keywords}

ADT Effects, White Blood Counts, Lymphocytes, Granulocytes

\section{Introduction}

Androgen deprivation therapy (ADT) has been shown to cause a decline in hemoglobin, leading to anemia in some patients [1] [2]. The exact mechanism remains uncertain [3]. The effect on other blood parameters such as white blood cell (WBC) counts is less well studied. Laboratory data show [4] that there are androgen receptors on leukocytes, raising the possibility of positive or negative 
effects. Mice lacking androgen receptors have been shown to have neutropenia with risk of infection [5]. It has also been shown that androgens can affect lymphocyte counts [6], although in humans there has minimal documented effect. Despite its wide spread use, there is minimal clinical data on the effect of androgen deprivation on overall leukocyte (white blood cell), granulocyte (neutrophil) or lymphocyte counts. The question remains relevant with the current interest in enhancing the immunotherapy approaches to cancer treatment. With the widespread use of androgen ablation in prostate cancer, it raises the question as to the effects of androgen ablation on leukocyte counts and whether such treatment enhances the suppressive effects of radiation therapy on those parameters.

\section{Material and Methods}

The transition to intensity modulated radiation therapy (IMRT) has changed the radiation dose distribution throughout normal tissue. While allowing a more focal delivery of the higher doses of radiation, the tradeoff is to deliver smaller doses to a larger volume. The larger radiation fields expose more normal tissue to radiation. Given the unknown consequence of this and in consideration of the known effect of radiation on blood components, we started routinely collecting complete blood counts $(\mathrm{CBC})$ on our prostate cancer patients who were receiving lymphatic (pelvic) radiation therapy. With institutional review board approval, we performed this retrospective review of prospectively collected (2014-2019) data. Complete blood counts were collected pretreatment and during the last week of treatment. Given the observation that there was an obvious decline in leukocytes (white blood counts, WBC) early on, we collected blood at the 3-month follow up visit to document recovery. Some of these patients had been started on neoadjuvant androgen ablation. This universally consisted of leuprolide injections; a few patients also received an antiandrogen short term. For those that were started on ADT in the radiation oncology clinic, a complete blood count was usually collected before starting. Our analysis is on the effect of androgen ablation alone on leukocyte (specifically granulocyte and lymphocyte) counts and whether androgen ablation enhanced the detrimental effects of radiation on those same counts.

Lymphatic radiation therapy consisted of $54 \mathrm{~Gy}$ delivered to the internal, external and common iliac lymphatics via linac based IMRT treatment. For post prostatectomy patients, the prostate fossa received a total of $70 \mathrm{~Gy}$ and for intact prostate, 78 Gy. Patient characteristics are shown in Table 1. The entire cohort was 311 patients. Ten did not go on to radiation after receiving ADT and are included in the pretreatment ADT analysis only. Three hundred one patients received radiation therapy. They were almost evenly divided between those that were $(n=162)$ and were not $(n=149)$ on short-term androgen ablation.

Worth noting is that in the literature outcomes are reported for either granulocytes or neutrophils. To be specific, granulocyte counts include neutrophils, basophils and eosinophils, with neutrophils being the predominant component 
Table 1. Patient characteristics.

\begin{tabular}{cc}
$\mathrm{N}=311$ & Mean $69.7 \mathrm{yrs}$ \\
Age & $69.7 \mathrm{yrs}$ \\
mean & $49.1-89.1 \mathrm{yrs}$. \\
range & \\
ADT & 162 \\
yes & 149 \\
no & \\
pelvis treatment & 250 \\
yes & 51 \\
no & \\
Total dose & 192 \\
78 Gy & 109 \\
70 Gy & \\
\hline
\end{tabular}

$\mathrm{ADT}=$ androgen deprivation therapy. ${ }^{*}$ includes: 4 with 70 Gy/28 fractions, 22 brachytherapy boost, 1 stereotactic body radiation therapy boost. 10 patients started $\mathrm{ADT}$ and did not receive radiation therapy.

$(>95 \%)$. Our lab reports the total granulocyte count. Also worth noting is that androgen deprivation therapy is facilitated via luteinizing hormone releasing hormone (LHRH) agonists (leuprolide) (or rarely a LHRH antagonist) alone. Sometimes treatment will include an antiandrogen which is then called total or combined androgen blockade (TAB, CAB).

\section{Statistics}

Sample characteristics were described using descriptive statistics. Frequencies and percentages were used to describe categorical variables. Means and standard deviations (or medians and ranges where appropriate) were used to describe continuous variables. A one-sample t-test (or Wilcoxon rank-sum test) was used to test for changes before and after androgen ablation. A two-sample t-test (or Wilcoxon rank-sum test when appropriate) was used to test for differences between patients who received neoadjuvant androgen ablation and those who did not. Statistical significance was set at $\mathrm{p}<0.05$.

\section{Results}

One hundred sixty-two patients received pre radiation therapy ADT. Sixty-three started ADT without a baseline $\mathrm{CBC}$ and 99 patients had a pre-ADT CBC. The median time on androgen ablation between measurements was 3 months (83 days). Results are shown in Table 2. Hemoglobin, WBC and granulocyte counts declined significantly, although the actual changes were small. Lymphocytes did not decline significantly. The mean HGB declined from $14.09 \mathrm{~g} / \mathrm{dL}$ to $13.51 \mathrm{~g} / \mathrm{dL}$ $(\mathrm{p} \leq 0.0001)$, mean $\mathrm{WBC}$ from $7.45 \times 10^{3} / \mu \mathrm{l}$ to $7.06 \times 10^{3} / \mu \mathrm{l}(\mathrm{p}=0.0222)$, mean 
Table 2. Effect of androgen deprivation therapy alone on parameters.

\begin{tabular}{cccccc}
\hline & N & Mean baseline & \multicolumn{2}{c}{ change } & P-value \\
\hline Hgb & 97 & $14.09 \mathrm{~g} / \mathrm{dL}$ & -0.58 & -0.50 & $<0.0001$ \\
WBC & 99 & $7.45 \times 10^{3} / \mu \mathrm{l}$ & -0.39 & -0.30 & 0.0222 \\
granulocytes & 94 & $4.53 \times 10^{3} / \mu \mathrm{l}$ & -0.32 & -0.32 & 0.0144 \\
lymphocytes & 94 & $1.98 \times 10^{3} / \mu \mathrm{l}$ & -0.03 & -0.01 & 0.8363 \\
\hline
\end{tabular}

$\mathrm{Hgb}=$ hemoglobin $\mathrm{WBC}=$ white blood cells.

granulocytes from $4.53 \times 10^{3} / \mu \mathrm{l}$ to $4.21 \times 10^{3} / \mu \mathrm{l}(\mathrm{p}=0.0144)$ and lymphocytes from a mean of $1.98 \times 10^{3} / \mu \mathrm{l}$ to $1.95 \times 10^{3} / \mu \mathrm{l}(\mathrm{p}=0.8363)$.

Next, we evaluated whether with radiation, the addition of ADT had a greater effect on the blood parameters. Overall, most patients (83\%) received lymphatic (pelvis) radiation followed by a prostate fossa $(\mathrm{n}=109)$ or prostate $(\mathrm{n}=192)$ boost. For the primary prostate patients, most patients (86\%) received a total external beam dose of $78 \mathrm{~Gy}$ and all the post radical prostatectomy patients received $70 \mathrm{~Gy}$. To control for confounding variables, we first evaluated whether the surgical status, the total dose or whether they had pelvic radiation influenced outcomes. We found that pretreatment, the post-surgery patients have a lower baseline $\mathrm{Hgb}$, total WBC and granulocyte count than the non-surgery patients, but the decline with treatment was no different. Pretreatment, the mean lymphocyte counts were similar, but the postoperative patients had a greater decline (from mean of 2.00 to $0.63 \times 10^{3} / \mu \mathrm{l}$ ) than the non-surgery patients (mean 1.99 to $\left.0.78 \times 10^{3} / \mu \mathrm{l}\right)(\mathrm{p}=0.0008)$. By three months after treatment, there was no difference in lymphocyte counts $(p=0.0642)$. Also, the total dose to the prostate/prostate fossa made no significant difference on any parameter. It was not unanticipated that the larger (pelvic) fields could influence the counts, but to confirm, we evaluated that specifically (Supplemental Table A1). The larger fields had a more profound effect on WBC, granulocyte and lymphocyte counts. We found that for the overall evaluation it did not change the outcomes due to the small number that did not receive pelvis radiation. For full transparency, we report the results for both the total and then for those only with pelvic radiation (Table 3, Table 4, respectively).

For the entire cohort, 162 patients received ADT and 149 did not. ADT did not affect the WBC decline $(\mathrm{p}=0.4583)$, granulocyte decline $(\mathrm{p}=0.3885)$, or lymphocyte decline $(\mathrm{p}=0.7755)$ at the end of radiation treatment (Table 3$)$. There was a greater decline in hemoglobin if on ADT $(p=0.0038)$.

At three months after treatment, compared to baseline there was no difference in hemoglobin ( $\mathrm{p}=0.3470), \mathrm{WBC}$ count $(\mathrm{p}=0.7517)$, granulocyte count $(\mathrm{p}=$ $0.7964)$ or lymphocyte count ( $\mathrm{p}=0.4226)$ between those on ADT and those not. The hemoglobin had recovered proportionally to the greater decline with treatment. There were subtle differences in the numbers, but the results were the same when evaluated by only patients that received pelvic radiation (Table 4). 
Table 3. All patients (with and without pelvis radiation).

\begin{tabular}{ccccccccc}
\hline HGB $(\mathrm{g} / \mathrm{dL})$ & $\mathrm{N}$ & $\begin{array}{c}\text { Baseline } \\
\text { (mean) }\end{array}$ & end & change & P-value & $\begin{array}{c}\text { Change from } \\
\text { months }\end{array}$ & Paseline & P-value \\
\hline No ADT & 143 & 14.32 & 13.48 & -0.84 & 0.0038 & 13.57 & -0.81 & \\
ADT & 151 & 13.57 & 12.46 & -1.14 & & 12.87 & -0.68 & 0.3470 \\
WBC $\left(\times 10^{3} / \mu \mathrm{l}\right)$ & & & & & & & & \\
No ADT & 143 & 6.93 & 4.97 & -1.95 & & 5.30 & -1.65 & \\
ADT & 151 & 6.90 & 4.75 & -2.09 & & 5.15 & -1.68 & 0.7517 \\
Granulocyte $\left(\times 10^{3} / \mu \mathrm{l}\right)$ & & & & & & & & \\
No ADT & 141 & 3.97 & 3.36 & -0.58 & & 3.44 & -0.55 & \\
ADT & 150 & 4.11 & 3.30 & -0.77 & & 3.44 & -0.65 & 0.7964 \\
Lymphocytes $\left(\times 10^{3} / \mu \mathrm{l}\right)$ & & & & & & & & \\
No ADT & 141 & 2.06 & 0.80 & -1.29 & & 1.07 & -1.00 & \\
ADT & 150 & 1.93 & 0.65 & -1.28 & & 0.94 & -0.98 & 0.4226 \\
\hline
\end{tabular}

Table 4. Only patients with pelvis radiation.

\begin{tabular}{ccccccccc}
\hline HGB (g/dL) & N & $\begin{array}{c}\text { Baseline } \\
\text { (mean) }\end{array}$ & end & change & P-value & 3 mos & $\begin{array}{c}\text { Change from } \\
\text { baseline }\end{array}$ & P-value \\
\hline No ADT & 106 & 14.40 & 13.44 & -0.95 & 0.0412 & 13.59 & -0.81 & 0.1782 \\
ADT & 144 & 13.63 & 12.46 & -1.18 & & 12.91 & -0.72 & \\
WBC $\left(\times 10^{3} / \mu \mathrm{l}\right)$ & & & & & & & & \\
No ADT & 106 & 6.81 & 4.64 & -2.16 & & 5.09 & -1.72 & 0.7160 \\
ADT & 144 & 6.70 & 4.71 & -2.16 & & 5.11 & -1.59 & \\
Granulocyte $\left(\times 10^{3} / \mu \mathrm{l}\right)$ & & & & & & & & \\
No ADT & 106 & 3.89 & 3.20 & -0.67 & & 3.38 & -0.51 & \\
ADT & 144 & 4.11 & 3.28 & -0.81 & & 3.42 & -0.69 & 0.7294 \\
Lymphocytes $\left(\times 10^{3} / \mu \mathrm{l}\right)$ & & & & & & & & \\
No ADT & 106 & 2.01 & 0.66 & -1.38 & & 0.93 & -1.08 & \\
ADT & 144 & 1.92 & 0.63 & -1.30 & & 0.92 & -1.29 & 0.1313 \\
\hline
\end{tabular}

\section{Discussion}

It is documented that androgen ablation consistently causes a drop in hemoglobin [1] [2]. We confirmed that short-term androgen ablation in our patients causes a modest $(\sim 0.5 \mathrm{~g} / \mathrm{dL})$, but still significant $(\mathrm{p} \leq 0.0001)$ drop in hemoglobin. Not well studied previously is the effect on granulocytes and lymphocytes. The finding of androgen receptors on leukocytes [4] raises the possibility that there will also be an effect on those components.

Our results show that short-term androgen ablation has a mild, but still significant negative effect on granulocytes and the total white blood count with no effect on lymphocytes. There is limited data in the literature. One study [7], showed no effect on total leukocyte counts, while another [3] showed a $9 \%$ decrease. There were no specifics as to granulocyte or lymphocyte counts in these 
studies, although in clinical studies [8] with the administration of testosterone, there was an increase in neutrophils. Chuang [5] reported a decrease in neutrophils in castrated mice, but non-significant decrease in neutrophils in 33 men after castration. In a similar small study $(n=16)$ [9] a significant increase in lymphocytes (including $\mathrm{T}$ cells and NK cells) occurred with TAB. The latter study is supported by mice data [10] [11] [12] [13] where it has been shown that there is a correlation with suppression of androgens and increased lymphocyte production. This is different from what we saw (no change) and was confirmed in a clinical series like ours [14]. In that study, nineteen patients received neoadjuvant total androgen blockade (an LHRH agonist and anti-androgen) and then pelvis radiation with a prostate radiation boost. From androgen ablation alone, the mean WBC count dropped from 6.37 to $6.19 \times 10^{3} / \mu \mathrm{l}\left(-0.18 \times 10^{3} / \mu \mathrm{l}\right)$, granulocytes from 4.34 to $4.10 \times 10^{3} / \mu \mathrm{l}\left(-0.24 \times 10^{3} / \mu \mathrm{l}\right)$, and lymphocytes (obtained by adding the subgroups) stayed the same from 1.64 vs. $1.66 \times 10^{3} / \mu \mathrm{l}$ $\left(+0.02 \times 10^{3} / \mu \mathrm{l}\right)$ ( $\mathrm{p}$ values not given). We saw changes of $-0.39 \times 10^{3} / \mu \mathrm{l},-0.32 \times$ $10^{3} / \mu \mathrm{l},-0.03 \times 10^{3} / \mu \mathrm{l}$, respectively.

Regarding the addition of androgen ablation to radiation therapy, it is thought to have a synergistic effect with radiation in the treatment and killing of prostate cancer. This raises the possibility of a synergistic effect that might be detrimental to blood components beyond that of radiation alone. We found no such effect on hemoglobin levels, granulocyte, lymphocyte or total white blood cell count. In addition, while recovery is incomplete at 3 months, there appeared to be no negative effect on recovery (Table 3 and Table 4).

The additive effects of ADT and radiation on Hgb levels has been infrequently reported. In a study [15] of 141 patients, 2 months of total androgen blockade (LHRH agonists and antiandrogen) resulted in a median drop of $1.6 \mathrm{~g} / \mathrm{dL}$ and after radiation, the total decline was $2.8 \mathrm{~g} / \mathrm{dl}$. We saw a smaller $(-1.17 \mathrm{~g} / \mathrm{dL}) \mathrm{de}-$ crease. The difference may be due to the use of total androgen blockade in that study versus the LHRH antagonist alone that we used.

We could find only one study similar to ours that evaluated the effect of adding androgen ablation to radiation [14]. For radiation without ADT, mean change in WBC count was 6.29 to $4.67 \times 10^{3} / \mu \mathrm{l}\left(-1.62 \times 10^{3} / \mu \mathrm{l}\right)$ vs 6.16 to $4.84 \times$ $10^{3} / \mu \mathrm{l}\left(-1.32 \times 10^{3} / \mu \mathrm{l}\right)$ for radiation plus ADT (non-significant); for granulocytes 4.26 to $3.74 \times 10^{3} / \mu \mathrm{l}\left(-0.52 \times 10^{3} / \mu \mathrm{l}\right)$ vs 4.1 to $3.81 \times 10^{3} / \mu \mathrm{l}\left(-0.29 \times 10^{3} / \mu \mathrm{l}\right)$, respectively (non-significant); and for lymphocytes 1.62 to $0.54 \times 10^{3} / \mu \mathrm{l}(-1.08 \times$ $10^{3} / \mu \mathrm{l}$ ) vs 1.68 to $0.68 \times 10^{3} / \mu \mathrm{l}\left(-1.0 \times 10^{3} / \mu \mathrm{l}\right)$, respectively ( $\mathrm{p}$-value not given for total lymphocytes). They reported that the $\mathrm{T}$ lymphocyte subgroup was more resistant than NK cells or B lymphocytes with addition of ADT. Overall, they confirmed that androgen ablation did not significantly affect the impact of radiation on blood parameters.

\section{Conclusion}

In conclusion, as in most series, we found that even short-term androgen abla- 
tion by itself causes a drop in hemoglobin. We also found that it caused a small, but still significant decline in WBC and granulocyte, but not lymphocyte counts When added to radiation therapy, ADT caused a greater decline in hemoglobin, but it recovered more quickly, so there was no difference at 3-month follow up. The combination of radiation with ADT did not cause a greater decline in WBC, granulocytes or lymphocyte counts compared to radiation therapy alone. Our findings would indicate that the addition of ADT should not have any effect on immune function beyond that of radiation therapy alone.

\section{Conflicts of Interest}

The authors declare no conflict of interest.

\section{References}

[1] Strum, S.B., McDermed, J.E., Scholz, M.C., Johnson, H. and Tisman, G. (1997) Anaemia Associated with Androgen Deprivation in Patients with Prostate Cancer Receiving Combined Hormone Blockade. British Journal of Urology, 79, 933-941. https://doi.org/10.1046/j.1464-410X.1997.00234.x

[2] Fonseca, R., Rajkumar, S.V., White, W.L., Tefferi, A. and Hoagland, H.C. (1998) Anemia after Orchiectomy. American Journal of Hematology, 59, 230-233. https://doi.org/10.1002/(SICI)1096-8652(199811)59:3\%3C230::AID-AJH8\%3E3.0.C $\underline{\mathrm{O} ; 2-2}$

[3] Gagliano-Jucá, T., Pencina, K.M., Ganz, T., Travison, T.G., Kantoff, P.W., Nguyen, P.L., et al. (2018) Mechanisms Responsible for Reduced Erythropoiesis during Androgen Deprivation Therapy in Men with Prostate Cancer. American Journal of Physiology-Endocrinology and Metabolism, 315, E1185-E1193. https://doi.org/10.1152/ajpendo.00272.2018

[4] Sader, M.A., McGrath, K.C., Hill, M.D., Bradstock, K.F., Jimenez, M., Handelsman, D.J., et al. (2004) Androgen Receptor Gene Expression in Leucocytes Is Hormonally Regulated: Implications for Gender Differences in Disease Pathogenesis. Clinical Endocrinology, 62, 56-63. https://doi.org/10.1111/j.1365-2265.2004.02173.x

[5] Chuang, K.H., Altuwaijri, S., Li, G., Lai, J.J., Chu, C.Y., Lai, K.P., et al. (2009) Neutropenia with Impaired Host Defense against Microbial Infection in Mice Lacking Androgen Receptor. Journal of Experimental Medicine, 206, 1181-1199. https://doi.org/10.1084/jem.20082521

[6] Olsen, N.J. and Kovacs, W.J. (2001) Effects of Androgens on T and B Lymphocyte Development. Immunologic Research, 23, 281-288.

https://doi.org/10.1385/IR:23:2-3:281

[7] Nishiyama, T., Ishizaki, F., Anraku, T., Shimura, H. and Takahashi, K. (2005) The Influence of Androgen Deprivation Therapy on Metabolism in Patients with Prostate Cancer. Journal of Clinical Endocrinology \& Metabolism, 90, 657-660. https://doi.org/10.1210/jc.2004-1611

[8] Gagliano-Jucá, T., Pencina, K.M., Guo, W., Li, Z., Huang, G. and Basaria, S. (2020) Differential Effects of Testosterone on Circulating Neutrophils, Monocytes, and Platelets in Men: Findings from Two Trials. Andrology, 8, 1324-1331. https://doi.org/10.1111/andr.12834

[9] Sutherland, J.S., Goldberg, G.L., Hammett, M.V., Uldrich, A.P., Berzins, S.P., Heng, T.S., et al. (2005) Activation of Thymic Regeneration in Mice and Humans Follow- 
ing Androgen Blockade. Journal of Immunology, 175, 2741-2753.

https://doi.org/10.4049/jimmunol.175.4.2741

[10] Viselli, S.M., Reese, K.R., Fan, J., Kovacs, W.J. and Olsen, N.J. (1997) Androgens Alter B Cell Development in Normal Male Mice. Cellular Immunology, 182, 99-104. https://doi.org/10.1006/cimm.1997.1227

[11] Roden, A.C., Moser, M.T., Tri, S.D., Mercader, M., Kuntz, S., Dong, H., et al. (2004) Augmentation of T Cell Levels and Responses Induced by Androgen Deprivation. Journal of Immunology, 173, 6098-6108. https://doi.org/10.4049/jimmunol.173.10.6098

[12] Ellis, T.M., Moser, M.T., Le, P.T., Flanigan, R.C. and Kwon, E.D. (2001) Alterations in Peripheral B Cells and B Cell Progenitors Following Androgen Ablation in Mice. International Immunology, 13, 553-558. https://doi.org/10.1093/intimm/13.4.553

[13] Erben, R.G., Eberle, J. and Stangassinger, M. (2001) B Lymphopoiesis Is Upregulated after Orchiectomy and Is Correlated with Estradiol but Not Testosterone Serum Levels in Aged Male Rats. Hormone and Metabolic Research, 33, 491-498. https://doi.org/10.1055/s-2001-16943

[14] Johnke, R.M., Edwards, J.M., Kovacs, C.J., Evans, M.J., Daly, B.M., Karlsson, U.L., et al. (2005) Response of T Lymphocyte Populations in Prostate Cancer Patients Undergoing Radiotherapy: Influence of Neoajuvant Total Androgen Suppression. Anticancer Research, 25, 3159-3166.

[15] Asbell, S.O., Leon, S.A., Tester, W.J., Brereton, H.D., Ago, C.T. and Rotman, M. (1996) Development of Anemia and Recovery in Prostate Cancer Patients Treated with Combined Androgen Blockade and Radiotherapy. Prostate, 29, 243-248. https://doi.org/10.1002/(SICI)1097-0045(199610)29:4\%3C243::AID-PROS5\%3E3.0. $\underline{\mathrm{CO} ; 2-\mathrm{C}}$ 


\section{Supplementary}

Supplemental Table A1. Effect of treatment volume (prostate/prostate fossa only versus whole pelvis) and androgen deprivation therapy (ADT).

\begin{tabular}{|c|c|c|c|c|c|c|c|c|c|}
\hline HGB (g/dl) & $\begin{array}{c}\text { Pelvis } \\
\text { treated }\end{array}$ & $\mathrm{n}$ & $\begin{array}{c}\text { Baseline } \\
\text { (mean) }\end{array}$ & end & change & P-value & 3 months & $\begin{array}{c}\text { Change from } \\
\text { baseline }\end{array}$ & $\mathrm{P}$-value \\
\hline \multirow[b]{2}{*}{ No ADT } & yes & 106 & 14.40 & 13.44 & -0.95 & \multirow[b]{2}{*}{0.0097} & 13.59 & -0.86 & \multirow[b]{2}{*}{0.6453} \\
\hline & no & 43 & 14.13 & 13.58 & -0.54 & & 13.54 & -0.70 & \\
\hline \multirow{2}{*}{$\mathrm{ADT}$} & yes & 144 & 13.63 & 12.46 & -1.18 & \multirow{2}{*}{0.0003} & 12.91 & -0.69 & \multirow{2}{*}{0.5062} \\
\hline & no & 8 & 12.76 & 12.36 & -0.40 & & 12.21 & -0.55 & \\
\hline \multicolumn{10}{|l|}{$\begin{array}{c}\text { WBC } \\
\left(\times 10^{3} / \mathrm{mcl}\right)\end{array}$} \\
\hline \multirow{2}{*}{ No ADT } & yes & 106 & 6.81 & 4.64 & -2.16 & \multirow{2}{*}{0.0040} & 5.09 & -1.70 & \multirow{2}{*}{0.2380} \\
\hline & no & 43 & 7.26 & 5.81 & -1.38 & & 5.80 & -1.51 & \\
\hline \multirow{2}{*}{$\mathrm{ADT}$} & yes & 144 & 6.87 & 4.71 & -2.16 & \multirow{2}{*}{0.0580} & 5.11 & -1.73 & \multirow{2}{*}{0.0472} \\
\hline & no & 8 & 6.69 & 5.60 & -1.09 & & 5.81 & -0.88 & \\
\hline \multicolumn{10}{|l|}{$\begin{array}{l}\text { Neutrophils } \\
\left(\times 10^{3} / \mathrm{mcl}\right)\end{array}$} \\
\hline \multirow{2}{*}{ No ADT } & yes & 106 & 3.89 & 3.20 & -0.67 & \multirow{2}{*}{0.1145} & 3.38 & -0.50 & \multirow{2}{*}{0.5473} \\
\hline & no & 43 & 4.19 & 3.79 & -0.34 & & 3.59 & -0.70 & \\
\hline \multirow{2}{*}{$\mathrm{ADT}$} & yes & 144 & 4.11 & 3.28 & -0.81 & \multirow{2}{*}{0.0451} & 3.42 & -0.66 & \multirow{2}{*}{0.0526} \\
\hline & no & 8 & 3.86 & 3.72 & -0.14 & & 3.76 & -0.09 & \\
\hline \multicolumn{10}{|l|}{$\begin{array}{l}\text { Lymphocytes } \\
\left(\times 10^{3} / \mathrm{mcl}\right)\end{array}$} \\
\hline \multirow{2}{*}{ No ADT } & yes & 106 & 2.01 & 0.66 & -1.38 & \multirow{2}{*}{0.0102} & 0.93 & -1.08 & \multirow{2}{*}{0.0092} \\
\hline & no & 43 & 2.19 & 1.15 & -1.04 & & 1.42 & -0.78 & \\
\hline \multirow{2}{*}{$\mathrm{ADT}$} & yes & 144 & 1.92 & 0.63 & -1.30 & \multirow{2}{*}{0.0244} & 0.92 & -1.00 & \multirow{2}{*}{0.0456} \\
\hline & no & 8 & 1.91 & 0.99 & -0.92 & & 1.17 & -0.74 & \\
\hline
\end{tabular}

The radiation volumes clearly have a marked effect on the decline in lymphocytes, somewhat less so for neutrophils. The lack of significant difference in the ADT subgroup likely reflects the small number of whole pelvis patients. Due to the significant difference that the volume makes on the blood counts and the imbalance between the ADT and no ADT groups in the percent of patients receiving whole pelvis radiation, further evaluation was limited to the large radiation field patients. 